\title{
MODELOS CULTURAIS: TEORIA, ESTUDOS E MÉTODOS
}

\author{
Heloísa Pedroso de Moraes Feltes \\ Universidade de Caxias do Sul \\ Área do Conhecimento de Humanidades \\ Caxias do Sul, RS, Brasil
}

\begin{abstract}
Resumo: Este artigo é uma revisão teórica sobre o construto modelos culturais, focalizando, inicialmente, suas definições em Antropologia Cognitiva, Linguística Cognitiva e Linguística Antropológica. Apresenta em seguida, como exemplo, quatro estudos em Linguística Cognitiva e Antropologia Cognitiva sobre modelos culturais que seguem metodologias, técnicas e procedimentos diferentes: o de RAIVA, os RACIONALISTA E ROMÂNTICO DE PADRONIZAÇÃO LINGUÍSTICA, o de CASAMENTO, e o JIHADISTA SUNITA DE RELAÇÕES POLÍTICAS. Na sequência, traz uma breve discussão sobre questões-problema a serem levantadas no tratamento de modelos culturais em Antropologia Cognitiva. As considerações finais desenvolvem uma análise geral dos métodos priorizados em investigações sobre modelos culturais.
\end{abstract}

Palavras-chave: Modelos Culturais. Linguística Cognitiva. Antropologia Cognitiva. Métodos.

\section{INTRODUÇÃO}

'Modelo cultural', como um construto teórico, é tratado na interface linguagem, cultura e cognição, constituindo, nas últimas quatro décadas, a ontologia de diferentes modelos teóricos em campos de investigação diversos (por exemplo, Antropologia, Ciências Cognitivas, Inteligência Artificial).

Esta revisão teórica tem duas motivações: (a) a proficuidade da interface linguagem humana, cognição e cultura, o que leva à interdisciplinaridade já construída entre as grandes áreas da Linguística, Antropologia e Ciências Cognitivas, e (b) a necessidade de mapear diferentes concepções de modelos culturais e métodos que permitem ao investigador reconstruí-los a partir de manifestações linguísticas, tendo como pressuposto a metáfora que orienta muitas pesquisas em Ciências Cognitivas: a da LINGUAGEM COMO JANELA PARA A MENTE.

O artigo inicia com uma seção dedicada a definições de modelos culturais a partir de autores da Antropologia Cognitiva, Linguística Cognitiva e Linguística Antropológica. Em seguida, na seção 3, a título de ilustração, descrevem-se quatro estudos que visam a reconstruir os seguintes modelos culturais: o de RAIVA (LAKOFF, 1987; LAKOFF; KÖVECSES, 1987; KÖVECSES, 1995, 2005); o de CASAMENTO (QUINN, 1987, 1997),

\footnotetext{
* Doutora em Letras - Linguística Aplicada pela Pontifícia Universidade Católica do Rio Grande do Sul. Professora do Programa de Pós-Graduação em Letras e Cultura da Universidade de Caxias do Sul. E-mail: helocogn@terra.com.br.
} 
os RACIONALISTA e ROMÂNTICO DE PADRONIZAÇÃO LINGUÍSTICA (GEERAERST, 2003) e o JIHADISTA SUNITA DE RELAÇÕES POLÍTICAS (SIECK, 2011). ${ }^{1} \mathrm{Na}$ seção 4 , apresenta-se a perspectiva de Kessing (1987) sobre questões problemáticas ligadas ao tratamento de modelos culturais. As considerações finais retomam e ampliam questões metodológicas relativas à pesquisa sobre modelos culturais.

\section{MODELOS CULTURAIS: ABORDAGENS TEÓRICAS}

Bennardo e Munck (2014), cuja obra é uma espécie de manual sobre fundamentos, teorias, métodos e aplicações relativos a modelos culturais, entendem, de modo geral, que modelos culturais são representações ou configurações mentais de conteúdo cultural minimamente saliente, compartilhadas por membros de uma cultura, as quais funcionam no sentido de dar sentido e interpretar inputs sensoriais, assim como produzir e dar forma a comportamentos intencionais e comunicativos. Para os autores, modelos culturais não são operações cognitivas, mas uma organização de conteúdo cultural estocado no cérebro. Modelos culturais são utilizados para ler intenções, atitudes, emoções e contexto social. Além disso, para os autores, modelos culturais são tipicamente flexíveis e fluidos. Isso se justifica pelo fato de que as pessoas podem não estar conscientes deles ou porque eles estão além da capacidade de elas os articularem. Esses modelos, como consequência, são usados em uma ampla variedade de situações por pessoas com diferentes perspectivas ou características psicológicas (por exemplo, história de vida, idade, status social). Entretanto, pode haver modelos culturais altamente específicos ou até mesmo prescritivos.

Bennardo e Munck, a partir da contribuição de diferentes autores, definem modelos culturais como organizações molares de conhecimento, cuja estrutura interna é composta de um núcleo (core) e nós "periféricos" que são preenchidos por valores padrão (default). Esses valores são instanciados - alterados para valores específicos ou deixados em seus valores padrão - quando o indivíduo experiencia “eventos" de qualquer natureza. A partir disso, surge a possibilidade de reconhecer e categorizar eventos como representantes do mesmo modelo cultural, mesmo que ligeiramente diferentes em cada uma das suas ocorrências específicas. ${ }^{2}$ A hipótese é a de que modelos culturais desempenham um papel importante na geração de comportamentos, e tais comportamentos são geralmente interpretados pelos outros como intencionais. Além disso, os autores defendem que modelos culturais são unidades fundamentais de análise para uma abordagem da cultura que vai além da dicotomia entre o indivíduo (a cultura apenas na mente) e o coletivo (cultura só no domínio social).

Kronenfeld (2008), por sua vez, entende modelos culturais como modelos cognitivos distribuídos que incorporam o conhecimento de como se comportar de diferentes formas, de como interpretar o comportamento de outros e de como definir a

\footnotetext{
${ }^{1}$ Em Feltes (2007), apresentamos de modo mais detalhado a análise de RAIVA e de modo mais superficial o de CASAMENTO. Neste artigo, damos a essas análises outra direção e mais especificidade para a questão dos modelos culturais subjacentes.

${ }^{2}$ Percebe-se a similaridade desta definição com a de frame (cf. MINSKY, 1975, p. 212).
} 
pertença a um grupo e, por consequência, entidades sociais. $\mathrm{O}$ autor vê modelos culturais como "unidades básicas de conhecimento cultural no que se refere à ação" (p. 176). E como se poderá constatar na abordagem de outros autores na sequência desta revisão teórica, Kronenfeld também associa o desenvolvimento das pesquisas sobre modelos culturais em Antropologia Cognitiva com a teoria dos esquemas da Psicologia Cognitiva e Inteligência Artificial. Para ele, esquemas são, de forma simplificada, estruturas cognitivas relacionadas a valores, objetivos, planos e conhecimento, processo e interpretação da ação. Tais esquemas "produzem o comportamento específico e detalhado de pessoas individuais" (2008, p. 200). Desse modo, "modelos culturais podem ser vistos simplesmente como esquemas que são amplamente compartilhados" (p. 200).

Em geral, no âmbito da Antropologia Cognitiva, um modelo consiste, de modo amplo, em um conjunto de elementos que se ajustam para representar algo (D'ANDRADE, 1995). D'Andrade (1987, p. 112) define modelo cultural (ou modelo folk) como "um esquema cognitivo que é intersubjetivamente compartilhado por um grupo social". Todo esquema, afirma o autor, é um modelo simples, uma representação de algum objeto ou evento. Ou seja, uma das propriedades de um esquema é a de ser uma organização abstrata da experiência.

Para D’Andrade (1987), “[u]m esquema é intersubjetivamente compartilhado quando todos num grupo conhecem o esquema, e todos sabem que alguém mais sabe o esquema, e todos sabem que alguém sabe que alguém sabe que alguém sabe o esquema" (p. 113, grifo do autor). O autor apresenta duas consequências dessa intersubjetividade: (a) as interpretações feitas sobre o mundo na base de um modelo folk são tratadas como se fossem fatos óbvios do mundo; e (b) uma grande parte da informação relacionada a um modelo folk não precisa ser explicitada. $\mathrm{O}$ autor esclarece que modelos folk são relativos ao conhecimento ou entendimento do senso comum das pessoas na vida cotidiana, em contraste com o conhecimento relativo aos modelos científicos e especializados. E mais: D’Andrade (1992) introduz a questão de que construtos psicológicos como esquemas e motivos podem dar conta de como a cultura se relaciona com a ação e defende que formas de motivação fazem a ligação entre cultura e ação. E a força de eliciação de um esquema pode depender de fatores específicos envolvidos em instâncias interpretativas.

Ainda nessa perspectiva, para Quinn e Holland (1987), modelos culturais

são pressupostos, modelos de mundo aceitos que são amplamente compartilhados (embora não necessariamente com a exclusão de outros modelos alternativos) pelos membros de uma sociedade e que desempenham um papel enorme em seu entendimento do mundo e seus comportamentos nele (p. 4).

Quinn (1997), com outras palavras, afirma que modelos culturais são esquemas culturais complexos que organizam todos os tipos de domínios da experiências, sejam eles de natureza perceptual, conceitual, relativos a objetos ou eventos, com o propósito de elaborar sistemas de conhecimento. Desse modo, organizam e inter-relacionam conjuntos de elementos, servindo como modelos operacionais para domínios de atividade no mundo. 
Strauss (2014), na mesma linha de pensamento, trata de modelos culturais a partir da noção de esquema. Para a antropóloga, esquemas culturais derivam de experiências compartilhadas, aprendidas; do que é experienciado pessoalmente por vários membros de um grupo ou daquilo que é comunicado entre eles. Esses esquemas são modelos locais de como operam os mundos natural, sobrenatural, interpessoal e sociopolíticos mais amplos. Eles são utilizados para acessar processos cognitivos e permitem explicar o modo como interpretamos percepções e emoções, reconstruímos memórias e planejamos as ações, atuando também na produção e interpretação de comportamento verbal e não verbal. Esquemas são simplificados e podem incluir conceitos genéricos como estereótipos, com ou sem crenças perniciosas, porque esquemas codificam nossas suposições relativas ao que é tipicamente associado com o quê. Da mesma forma que D'Andrade (1992), Strauss entende que uma das características dos modelos culturais é que eles se conectam com sentimentos e motivações, ou seja, eles têm uma "força diretiva", no sentido de que não são explanações neutras, já que carregam avaliações e objetivos que motivam a ação.

Quinn e Holand (1987) estabelecem uma diferença entre as propostas de linguistas e de antropólogos quanto à forma de abordar tais modelos ou esquemas cognitivos. Dizem que os linguistas se preocupam com as implicações dos modelos culturais subjacentes para teorias sobre metáforas, polissemia entre outros fenômenos linguísticos. Nesse sentido, os modelos culturais são a chave para o uso linguístico. Já os antropólogos vão numa direção oposta ao tratarem os usos linguísticos "como pistas para modelos culturais subjacentes, trabalhando em direção a uma teoria mais satisfatória da cultura e seu papel em tais tarefas não linguísticas [...], avaliando o comportamento de outros" (1987, p. 24). Aqui o uso linguístico são os melhores dados para a reconstrução dos modelos culturais.

Sieck (2011) adota uma noção de cultura como conhecimento compartilhado da Antropologia Cognitiva, mas na perspectiva epidemiológica de Dan Sperber. Para Sperber (1985), a mente dos seres humanos é suscetível a representações mentais do mesmo modo que são suscetíveis a doenças. E esclarece:

\footnotetext{
Entendo [...] as explicações causais de fatos culturais como necessariamente incorporadas em um tipo de epidemiologia das representações. Há, para começar, algumas similaridades superficiais óbvias. Por exemplo, uma representação pode ser cultural de diferentes formas: algumas são lentamente transmitidas ao longo de gerações; elas são o que chamamos de tradições e são comparáveis a endemias; outras representações, típicas das culturas modernas, espalham-se rapidamente através de uma população toda, mas têm uma vida curta de span; elas são o que chamamos modismo e são comparáveis a epidemias. (SIECK, 2011, p. 74)
}

Desse modo, para Sperber, o termo 'epidemiologia cultural' diz respeito ao modo como ideias são distribuídas entre uma população.

Sieck, Rasmussen e Smart (2010), seguindo a perspectiva epidemiológica, partem do reconhecimento de que as mentes individuais contêm grande quantidade de conteúdo mental, e o termo 'ideia' se refere a qualquer conteúdo mental sobre concepções de como as coisas são ou como elas deveriam ser. Como consequência, redes de ideias constituem teorias folk ou modelos mentais, os quais, por sua vez, resultam em julgamentos e decisões que afetam o comportamento das pessoas. 
Para os autores, modelos mentais estão na "cabeça" dos indivíduos e, quando indivíduos entram em contato uns com os outros, geram-se pensamentos associados que produzem modelos mentais que se assemelham uns aos outros. Ocorre que, quando modelos mentais se espalham dentro de uma população e persistem por longos períodos de tempo, eles se tornam modelos culturais, ou seja, há o compartilhamento de uma rede de conteúdos mentais (ideias) entre os membros dessa população.

Sieck (2011) afirma que seu método compartilha algumas características com abordagens como a de D'Andrade em Antropologia Cognitiva, mas oferece alguns elementos distintos, tais como a ênfase em assegurar a relevância de modelos culturais para a tomada de decisões, no sentido de fornecer uma ligação mais direta com o comportamento real no interior de uma cultura (perspectiva 'êmica'); de modelar redes inter-relacionadas de ideias; e de buscar estimar a prevalência de ideias numa network, o que evitaria confiar em noções vagas como a de "compartilhamento" de ideias.

No âmbito da Linguística Cognitiva, Kövecses (1995) diz adotar a definição de cultura dos antropólogos cognitivos, ou seja, o de "cultura como um conjunto de entendimentos compartilhados sobre o mundo" (p. 49). Kövecses (2005) posiciona-se da seguinte forma:

[...] na visão de cultura com a qual tenho trabalhado [...] há uma noção [...] que desempenha um papel crucial: aquela de modelos culturais. Modelos culturais são importantes em nossas tentativas de descrever e caracterizar o sistema conceptual humano e, consequentemente, a cultura. [...] Modelos culturais são melhor concebidos como quaisquer organizações coerentes da experiência humana compartilhadas por pessoas. (p. 193).

Geeraerst (2004), por sua vez, afirma que:

[é] comum a ideia em Linguística Cognitiva de que modelos culturais que subjazem ao raciocínio e à argumentação são em alguma medida entidades idealizadas [...], são em alguma medida abstratos, gerais, até mesmo simplistas, precisamente porque os usamos para fazer sentido de fenômenos que são intrinsecamente mais complicados. (p. 49).

Para o autor, no que diz respeito a fenômenos sociais, modelos culturais podem ser entidades idealizadas, mas também ideológicas. Modelos culturais podem ser ideologias: (a) quando seu caráter idealizado é esquecido: quando é negligenciada a diferença entre o modelo abstrato e as circunstâncias reais; ou (b) quando são utilizados de forma prescritiva ou normativa: "quando são utilizados como modelos de como as coisas deveriam ser em vez de como as coisas são" (GEERAERST, 2004, p. 49). No primeiro caso, "uma ideologia é sempre, em certa medida, um acobertamento, um simulacro, uma deturpação deliberada da situação real, e uma descrição de tais ideologias deve ser necessariamente crítica". No segundo caso, para Geeraerts, "uma ideologia é basicamente um guia para a ação social, um sistema compartilhado de ideias para a interpretação da realidade social a despeito da avaliação dos pesquisadores sobre essa perspectiva" (p. 49).

Já para Palmer (2007), como linguista antropológico, modelos cognitivos idealizados, mapas, domínios da experiência esquema de imagens, metáforas e metonímias conceituais, protótipos, categorias complexas, categorias radiais e 
conhecimento enciclopédico apresentam, quase sempre, componentes culturais, na medida em que tomam formas específicas a partir do que os falantes aprendem ao longo de sua socialização e aculturação. Palmer esclarece: "[m]odelos cognitivos que são culturalmente específicos podem ser denominados modelos culturais" (p. 1046, grifo nosso).

Como é possível observar, o entendimento do que é um modelo cultural varia entre os diferentes autores, mas pode-se dizer, resumidamente, de que se trata de um construto teórico que abarca: (a) a ideia de ser uma entidade idealizada com alto grau de simplificação; (b) a noção de esquemas cognitivos complexos, relativos a todos os domínios da experiência humana (perceptual, conceptual e sociocultural), que estruturam sistemas de conhecimento; (c) a condição de ser intersubjetivamente compartilhado em uma cultura, grupo social ou comunidade; (d) a relação com valores, motivação, objetivos, expectativas, sentimentos e emoções; (e) a função de organizar domínios de conhecimento de modo a servir de modelo para a eliciação e interpretação das ações humanas; (f) o entendimento de que pode ter natureza ideológica; e (g) a condição de não ser diretamente acessível, devendo ser "abstraído" ou "reconstruído" a partir da linguagem e/ou comportamento humano.

3 MODELOS CULTURAIS: ESTUDOS

3.1 MODELO CULTURAL DE RAIVA

Kövecses (1995) afirma que há um modelo cultural de RAIVA que é compartilhado pelos falantes da língua inglesa americana e que é parte da cultura como um todo, no sentido de que um contexto cultural mais amplo impacta sobre como modelos culturais são conceptualizados.

Lakoff e Kövecses (1987) dizem que o estudo sobre RAIVA se baseia em suas próprias observações intuitivas, e que são necessários estudos empíricos para verificar sua consistência. Consideram que, estando certos, o modelo cultural proposto para RAIVA teria "realidade psicológica", mas permanece indeterminado tanto o grau dessa realidade psicológica, assim como de que tipo ela é. Em outras palavras, Lakoff (1987) alerta para o fato de que sua metodologia (e a de Kövecses) não o capacita a falar do status psicológico do modelo de RAIVA. Sobre isso, indaga: "Quanto dele as pessoas utilizam para compreender raiva? As pessoas baseiam suas ações nesse modelo? As pessoas são conscientes do modelo? [...] E de forma mais intrigante, o modelo tem algum efeito sobre o que as pessoas sentem?" (p. 408). O que é claro é que "a evidência linguística é um guia extraordinariamente preciso de tais modelos" (LAKOFF; KÖVECSES, 1987, p. 221).

Segundo Lakoff (1987), Lakoff e Kövecses (1987) e Kövecses (1995), o estudo da emoção raiva revela que os modelos culturais fazem uso de mecanismos imaginativos, como metáfora, metonímia, cenários abstratos; e que os modelos culturais podem ser motivados pela experiência corpórea e, portanto, não são puramente imaginativos. 
Lakoff (1987) inicia sua análise ${ }^{3}$ com a apresentação da teoria popular do senso comum sobre os efeitos fisiológicos da raiva: "Os efeitos fisiológicos da raiva são aumento de calor do corpo, aumento da pressão interna (pressão sanguínea, pressão muscular), agitação e interferência na percepção" (p. 381). Segundo a teoria popular, se a raiva cresce, os seus efeitos fisiológicos também crescem, até um ponto em que tais efeitos prejudicam o funcionamento normal do organismo.

Quando aplicada a coisas fluidas, a metáfora geral é RAIVA É O CALOR DE UM FLUIDO NUM RECIPIENTE, motivada por CALOR, PRESSÃO INTERNA e AGITAÇÃO. Quando aplicada a coisas sólidas, a metáfora passa a ser RAIVA É FOGO, motivada por CALOR E VERMELHIDÃO. Essas metáforas específicas seriam mais elaboradas, principalmente porque se baseiam numa metáfora mais geral do sistema conceitual global: O CORPO É UM RECIPIENTE PARA AS EMOÇÕES, expressa, por exemplo, em: Ela não podia conter sua alegria.

No caso da metáfora A RAIVA É O CALOR DE UM FLUIDO NUM RECIPIENTE, há, de um lado, a ideia de calor associada à presença da raiva; de outro, a de frio associada à sua ausência, como em (a) Você faz o meu sangue ferver e (b) Fique frio.

Lakoff divide as correspondências entre o domínio-fonte (FLUIDO NUM RECIPIENTE) e o domínio-alvo (RAIVA) em dois tipos: as ontológicas, relativas à correspondência de entidades num e noutro domínio, e as epistemológicas, relativas a "correspondências entre os conhecimentos sobre o domínio-fonte e o conhecimento correspondente sobre o domínio-alvo" (p. 387). Assim, de um lado, teríamos as seguintes correspondências ontológicas: (a) o recipiente é um corpo, (b) o calor do fluido é a raiva, (c) a escala do calor é a escala da raiva, (d) o calor do recipiente é o calor do corpo, (e) a pressão no recipiente é a pressão interna no corpo, (f) a agitação do fluido e do recipiente é a agitação física, (g) a explosão é a perda de controle; e (h) a frialdade no fluido é a ausência de raiva.

De outro lado, teríamos, por exemplo, as seguintes correspondências epistemológicas:

O efeito do calor intenso do fluido é o calor do recipiente, pressão interna e agitação.

$\rightarrow \mathrm{O}$ efeito da raiva intensa é o calor do corpo, pressão interna e agitação.

Não o provoque, ele logo fica esquentado!

\section{Ela pulava de raiva.}

\section{Ele ficou vermelho de raiva.}

Se ultrapassado um certo limite de aquecimento do fluido, a pressão aumenta até o ponto em que o recipiente explode.

$\rightarrow$ Se ultrapassado um certo limite de aumento da raiva, a pressão aumenta até o ponto em que a pessoa perde o controle.

Ele quase teve uma hemorragia ao falar no assunto.

\footnotetext{
${ }^{3}$ Essa análise é apresentada, de diferentes formas, em Lakoff (1987), Lakoff e Kövecses (1987) e Kövecses (1995). O trânsito por essas diferentes publicações justifica-se apenas pela forma como alguns aspectos na análise são tratados.
} 
Não toleramos mais suas explosões.

Eu estava tão furioso que nem podia ver direito.

Ele estava fora de si.

Com base nessas correspondências, é construído o cenário prototípico da RAIVA, o qual tem cinco estágios temporais:

Vítima/Self $=\mathbf{S}$

Agente de Retribuição/Self $=\mathbf{S}$

Alvo da Raiva $=$ Malfeitor $(\mathbf{M})$

Causa Imediata da Raiva= Evento Ofensivo $(\mathbf{E O})$

Comportamento Ofensivo = Retribuição $(\mathbf{R})$

\section{ESTÁGIO 1 - EVENTO OFENSIVO}

$\mathbf{M}$ ofende $\mathbf{S}$ [intencional e injustamente].

$\mathbf{M}$ está em falta com $\mathbf{S}$ [M está enganado e $\mathbf{S}$ é inocente].

O EO degrada $\mathbf{S}$.

A intensidade da ofensa supera a intensidade da $\mathbf{R}$ [que é igual a zero neste ponto], criando um desequilíbrio.

A ofensa provoca a raiva.

ESTÁGIO 2 - RAIVA

A raiva existe.

S experimenta efeitos fisiológicos [aumento da temperatura corporal e da pressão interna, agitação física].

A raiva exerce força sobre $\mathbf{S}$ para tentar um ato de $\mathbf{R}$ a $\mathbf{M}$.

ESTÁGIO 3 - TENTATIVA DE CONTROLE

$\mathbf{S}$ exerce uma contraforça na tentativa de controlar sua raiva [porque os atos de $\mathbf{R}$ são danosos e/ou socialmente inaceitáveis].

ESTÁGIO 4 - PERDA DE CONTROLE

A intensidade da raiva vai além do limite.

A raiva toma o controle de $\mathbf{S}$.

$\mathbf{S}$ exibe comportamento raivoso [perda do julgamento, ações agressivas].

Há danos em $\mathbf{S}$ [fora do controle não é responsável por suas ações].

Há perigo para $\mathbf{M}$.

ESTÁGIO 5 - ATO DE RETRIBUIÇÃO

$\mathbf{S}$ realiza um ato de $\mathbf{R}$ contra $\mathbf{M}$ [em geral, um comportamento raivoso dirigido a $\mathbf{M}$ ].

A intensidade $\mathbf{R}$ equilibra a intensidade da ofensa [o que equilibra a escala da justiça].

A intensidade da raiva cai para zero.

A raiva desaparece. 
Os casos não prototípicos de RAIVA seriam, por exemplo:

RAIVA INSATISFEITA: No estágio 5, a intensidade da raiva continua alta.

RAIVA REDIRECIONADA: Em vez de direcionar a raiva para $\mathbf{M}, \mathbf{S}$ direciona-a para uma outra pessoa ou coisa.

RESPOSTA CONTROLADA: S mantém-se sob controle e não chega ao ato de $\mathbf{R}$.

EXPLOSÃO IMEDIATA: $\mathbf{S}$ sente a raiva e, de uma vez, perde o controle.

Lakoff e Kövecses (1987) afirmam que a metáfora RAIVA É CALOR é baseada no "modelo cultural dos efeitos fisiológicos de raiva, segundo o qual o aumento do calor do corpo é o principal efeito da raiva" (p. 203). Esse modelo cultural também sustenta que outro efeito importante é a agitação, que é parte de nosso modelo cultural de INSANIDADE. A sobreposição entre os modelos culturais dos efeitos de raiva e insanidade provê a metáfora: RAIVA É INSANIDADE, como se pode constatar na expressão que manifesta raiva: Eu estou louco. Segundo os autores, em nosso modelo cultural, a raiva é vista como uma emoção negativa, que produz reações fisiológicas indesejáveis, as quais conduzem à inabilidade de agir normalmente e, ao mesmo tempo, é perigosa para os demais. Reconhecendo esse perigo, a pessoa raivosa passa a ver a raiva como um oponente. Desse modo, surge a metáfora A RAIVA É UM OPONENTE, como em Estou lutando contra minha raiva.

Com relação a essa análise de RAIVA, Quinn e Holand (1987) sustentam que, porque as primeiras análises feitas por Lakoff e colaboradores não se basearam em discursos sistematicamente coletados, há pelo menos duas consequências: (a) o corpus de metáforas utilizadas em um dado domínio é incompleto, e os resultados obtidos são tendenciosos e maldirecionados, como superestimar a afirmação de que FLUIDO NUM RECIPIENTE seria a metáfora central para RAIVA; e (b) as metáforas fora do contexto de seu uso efetivo em discurso não garantem sua verificabilidade, pois somente um estudo dessa natureza poderia dar conta do modo como as metáforas são internalizadas e utilizadas, revelando, assim, como operam. ${ }^{4}$

3.2 MODELOS CULTURAIS RACIONALISTA E ROMÂNTICO DE PADRONIZAÇÃO LINGUÍSTICA

Geeraerts (2003) argumenta que o modo de pensar sobre questões de variação e padronização linguísticas pode, de um modo geral, ser reduzido a modelos culturais subjacentes e opostos: o modelo cultural RACIONALISTA e o modelo cultural ROMÂNTICO.

Seu estudo parte de teorias sobre as origens da linguagem formuladas, inicialmente, no século XVIII, no qual ele situa as fontes intelectuais das concepções romântica e racionalista, assim como a tensão entre elas, tendo como base o ponto de vista de Johann Gottfried Herder (em Abhandlung über den Ursprung der Sprache, 1772), Skutnabb-

\footnotetext{
${ }^{4}$ Naturalmente, nos últimos 30 anos desde esta crítica, a Linguística Cognitiva avançou no sentido de ser uma abordagem baseada no uso, partindo de eventos de fala e discursos naturais.
} 
Kangas (em Linguist genocide in education - or Wordwide diversity and human rights?, 2000), Verlooy (Verhandeling op d'Onacht der Moederlyke Tael in de Nederlanden, 1788), Etienne Bonnot de Condillac (em Essai sur l'Origines des Sciences humaines, 1746), Bertrand Barére (em Rapport du Comité de Salut Public sur les idiomes, 1794) e Henri-Baptiste Grégoire (em Rapport sur la nécessité et les moynes d'anéantir les patois et d'universaliser l'usage de la langue française, 1794).

Geeraerts analisa fragmentos das obras desses filósofos, evidenciando, num primeiro momento, que a abordagem romântica inicia com uma concepção expressiva da linguagem, enquanto a racionalista tem como ponto de partida uma concepção comunicativa da linguagem. Na perspectiva romântica, as línguas são primariamente expressivas: elas expressam uma identidade à medida que incorporam uma concepção particular do mundo, uma visão de mundo, e, assim sendo, a imposição de uma língua padrão pode discriminar identidades culturais específicas. Na perspectiva racionalista, a língua comum tem uma função emancipatória, como um instrumento de participação política e educacional.

O autor, nessa pesquisa, pergunta-se: (a) Se a língua é uma realidade social e cultural, quais são os modelos [culturais] que dão forma à nossa concepção de língua? (b) Especificamente, quais são os modelos que dão forma ao nosso pensamento sobre a língua como um fenômeno social? (c) Quais são os paradigmas que utilizamos para pensar sobre a língua, não primariamente em termos de estrutura linguística, mas em termos de variação linguística: modelos sobre a forma como as variedades da língua estão distribuídas em uma comunidade linguística e sobre a forma como tal distribuição pode ser avaliada? Conforme Geeraerts, para responder a essas questões é necessário explorar a estrutura subjacente e o desenvolvimento histórico de dois modelos culturais que competem entre si e que se encontram na base das políticas linguísticas e educacionais nos debates sobre a padronização linguística. Segundo ele, há duas possibilidades de abordagem: variedades de análises críticas do discurso ou de ideologias da linguagem. As primeiras analisam criticamente o texto com relação à sua posição (reproduzir ou antagonizar) no jogo de forças sociais existentes. As segundas concentram-se em como as crenças sobre variação linguística e variedades linguísticas específicas manifestam-se explícita ou implicitamente, respectivamente, (i) em políticas linguísticas e práticas educacionais (ii) e em como interagem com questões identitárias, econômicas, organizações políticas, etc.

É na perspectiva da segunda abordagem que o autor discrimina dois modelos culturais sobre a padronização e variação linguística: o modelo RACIONALISTA e o modelo ROMÂNTICO. Sumariamente, o autor apresenta os resultados que revelam a relação dialética entre os dois modelos e, em seguida, suas características, numa perspectiva temporal contemplando o $\left(^{*}\right)$ século XVIII com modelos culturais básicos; (**) o século XIX com a transformação nacionalista dos modelos; e (***) o século XX, com a transformação pós-moderna desses modelos:

\section{MODELO CULTURAL RACIONALISTA}

A linguagem é um meio de comunicação.

Há um ideal democrático: a padronização é um meio neutro de participação social. 
A variação da linguagem impede a emancipação.

(*) A língua comum é um instrumento de participação política e educacional.

(**) A nação é a base da democracia liberal.

(***) O inglês global é uma oportunidade, e o multilinguismo é uma especialização funcional.

\section{MODELO CULTURAL ROMÂNTICO}

A língua é um meio de expressão.

Há um criticismo anti-ideológico: a padronização é um meio de exclusão social.

A variação da linguagem expressa diferentes identidades.

(*) A língua padrão é vista como discriminatória de identidades específicas.

(**) A nação é o foco da identidade cultural e étnica.

(***) O inglês global é uma ameaça, e o multilinguismo é a expressão de identidades pósmodernas fragmentadas.

Com essas distinções o autor quer mostrar que "faz sentido pensar sobre os processos reais de padronização [linguística] em termos de modelos culturais". Tais modelos culturais são reais "não apenas à medida que eles dão forma a debates públicos, mas também à medida que repousam na base das atitudes linguísticas dos usuários da língua" (GEERAERTS, 2004, p. 81). Ou seja, os dois modelos podem ser utilizados para examinar debates e argumentações numa análise de discurso, assim como podem dar forma a atitudes linguísticas de comunidades linguísticas. Se sua presença for real, tais modelos aparecem não apenas no modo como as pessoas falam sobre padronização, mas também no modo como elas agem com relação a essa padronização. De qualquer modo, segundo o autor, além de prover um melhor entendimento da lógica subjacente aos debates sobre padronização, a ligação entre esses modelos e as atitudes linguísticas poderiam conduzir a pesquisas empíricas, como um possível desenvolvimento dessa discussão inicial.

\subsection{MODELO CULTURAL DE CASAMENTO}

Um exemplo de estudo antropológico de modelos culturais é o de Quinn (1987). A autora entrevistou, separadamente, maridos e esposas em 11 casamentos (22 sujeitos). Cada entrevista teve uma média de 15 a 16 horas de duração (em diferentes sessões) e topicalizava o casamento desses casais. A autora identificou, em seu corpus geral, oito esquemas do tipo "proposição' ${ }^{5}$ recorrentes a partir de metáforas sobre a durabilidade do casamento, o benefício mútuo que dele se segue, a falta de conhecimento em seu início, dificuldades e o esforço que requer; e três esquemas-tipo proposição que não aparecem

\footnotetext{
${ }^{5}$ Como a autora explica, o uso da expressão esquema-proposição sugere que há o reconhecimento de que os esquemas mentais podem organizar outros "materiais" além do que é proposicional.
} 
em todo o corpus, mas que parecem desempenhar, também, um papel significativo no modelo cultural de casamento dos americanos, que são a do casamento como compartilhamento, como bem-sucedido ou sujeito ao fracasso e como risco. Constitutivos desse modelo cultural, tem-se, em suma, oito esquemas-proposição:

CASAMENTO É DURADOURO

CASAMENTO É MUTUAMENTE BENÉFICO

CASAMENTO É DESCONHECIDO NO PRINCÍPIO

CASAMENTO É DIFÍCIL

CASAMENTO É ESFORÇO

CASAMENTO É COMPARTILHAMENTO

CASAMENTO PODE SER BEM-SUCEDIDO OU FRACASSAR

CASAMENTO É RISCO.

Quinn (1987) afirma que as metáforas para CASAMENTO fornecem um conjunto de pistas para o modelo cultural de casamento subjacente aos discursos, por exemplo:

\section{O CASAMENTO É UM PRODUTO MANUFATURADO}

("Cada uma [das experiências] é tipo como construindo uma a outra, que nossa relação fica mais sólida com o tempo.")

\section{O CASAMENTO É UMA JORNADA EM CURSO}

("[...] temos sido capazes de trabalhar ao longo de muitas lutas em nosso casamento e estar num lugar agora onde nós confiamos um no outro [...] E eu me sinto muito confiante sobre ser capaz de continuar este caminho e continuar trabalhando qualquer outra coisa que aparecer. [...] Poderia ter ido em direções muito diferentes [...]. Mas penso que ambos temos muito crédito pela direção em que seguimos [...].”)

\section{O CASAMENTO É UM ELO DURADOURO ENTRE DUAS PESSOAS}

(Expressões nas entrevistas: "acimentados juntos" (cemented together), "ligados juntos", "amarrados um ao outro" "uma relação gelled".)

O CÔNJUGE É UMA PARTE AJUSTADA (FITTING PART)

(“A melhor coisa sobre Bill, para mim, é que ele se ajusta a mim tão bem.")

O CASAMENTO É UM INVESTIMENTO

("Por que neste momento você quer parar e não conseguir aproveitar todos os anos que você já gastou junto?")

Quinn (1987) afirma que um esquema prototípico ou idealizado pode funcionar para tarefas de raciocínio. Essas tarefas são mediadas por um modelo mental fornecido culturalmente, "inventado" para esse propósito na forma de uma sequência prototípica ou idealizada de eventos maritais. Cada evento está ligado ao outro, gerando uma sequência de relações causais. A idealização realiza-se através do raciocínio natural dos entrevistados sobre casamento, usando metáforas que fornecem excelentes pistas sobre as suposições compartilhadas.

Para a autora, haveria duas formas de idealização. Na primeira, os eventos são bem circunscritos, em número limitado, seguindo-se um ao outro numa ordem invariante: durabilidade, compartilhamento, benefício mútuo, realização, compatibilidade, 
dificuldade, esforço, sucesso, risco ou falha. Os casamentos são idealmente duráveis, compartilhados e mutuamente benéficos; os benefícios são uma questão de realização; os esposos devem ser compatíveis, a fim de prover as necessidades mútuas, o que faz com que seus casamentos sejam satisfatórios e benéficos. Realização e compatibilidade são difíceis de alcançar, mas essas dificuldades podem ser superadas com esforço. Se isso não ocorre, o casamento corre o risco de falhar. Na segunda idealização, as relações entre os pares de eventos na sequência são simplificadas. Um casamento bem-sucedido é durável, e o casamento durável é sempre bem-sucedido. Um casamento benéfico é durável e, sendo durável, é benéfico. Sendo benéfico, traz realização. Compatibilidade é benéfica e, se não for, não há compatibilidade. Incompatibilidade causa dificuldade, e apenas a compatibilidade supera a dificuldade com esforço. $\mathrm{O}$ esforço é um requisito necessário, mas não suficiente. Algumas dessas relações causais no raciocínio são ilustradas abaixo por meio de partes dos esquemas-proposição:

$$
\begin{array}{ll}
\text { DESCONHECIDO NO PRINCÍPIO } & \rightarrow \sim \text { MUTUAMENTE BENÉFICO } \\
\sim \text { MUTUAMENTE BENÉFICO } & \rightarrow \text { DIFÍCIL } \\
\text { [DIFÍCIL } & \rightarrow \sim \text { DURADOURO }] \\
\hline \text { DESCONHECIDO NO PRINCÍPIO } \rightarrow \sim \text { DURADOURO } \\
\\
\text { DESCONHECIDO NO PRINCÍPIO } & \rightarrow \sim \text { MUTUAMENTE BENÉFICO } \\
{[\sim \text { MUTUAMENTE BENÉFICO }} & \rightarrow \text { DIFÍCIL] }
\end{array}
$$

\begin{tabular}{|c|c|c|}
\hline [ ESFORÇO & $\rightarrow$ & DIFÍCIL] \\
\hline DIFÍCIL & $\rightarrow$ & DURADOURO \\
\hline ESFORÇO & $\rightarrow$ & DURADOURO \\
\hline
\end{tabular}

DESCONHECIDO NO PRINCÍPIO $\rightarrow$ DIFÍCIL

Quinn (1997) conclui que é preciso discernir o padrão de raciocínio subjacente, interno e observável de diferentes falantes de línguas variadas sobre experiências maritais. Por isso, a estrutura deve ser descoberta através de raciocínio verbal, por meio do desempenho em tarefas cognitivas, em uma etnografia da vida interior. Quinn afirma que parte da dificuldade de encontrar o padrão linguístico subjacente à variação linguística é a necessidade de, ao interpretar passagens de discurso, decodificar as várias metáforas que os falantes usam para falar de benefício, esforço, sucesso, por exemplo, assim como as construções causais usadas para conectar esses termos.

Além disso, para Quinn, muitos dos esquemas culturais para raciocinar sobre casamento podem vir de várias fontes públicas como programas de TV, livros, etc., as quais desempenham o papel de disseminar as mesmas sequências idealizadas e reforçálas na mente dos indivíduos, ao mesmo tempo que distorcem, em diferentes graus, os esquemas originais. Essas contradições culturais podem ser disseminadas por períodos curtos de tempo e evocam conflitos internos profundos para os quais não há uma solução cultural automática. Ao analisar esses achados, Quinn (1997) defende que o padrão de 
uso dessas metáforas reflete um esquema subjacente que as pessoas compartilham para pensar sobre casamento e que guia a seleção das metáforas.

Finalmente, para Quinn (1997), não há "o" modelo cultural de casamento para os americanos, do modo como se referia em Quinn (1987), mas "um" modelo cultural de CASAMENTO, porque o conjunto de entendimentos compartilhados varia de cultura para cultura e pode diferir em outras sociedades.

\subsection{MODELO CULTURAL JIHADISTA SUNITA DE RELAÇÕES POLÍTICAS}

Sieck (2011), a partir da abordagem epidemiológica de cultura, descrita anteriormente de forma breve, procura analisar o modelo cultural JIHADISTA SUNITA DE RELAÇÕES POLÍTICAS, ou seja, a base cognitiva do terrorismo.

O pesquisador utiliza a Cultural Network Analysis (CNA) como um método para descrever ideias que são compartilhadas por membros de um grupo social e que são relevantes para a tomada de decisões em situações particulares. Neste ponto é importante esclarecer o que Sieck entende por grupo cultural. O termo 'grupo cultural' "refere-se a uma população ou subpopulação de pessoas que compartilham em larga escala ideias interconectadas de interesse" (SIECK, 2011, p. 6).

A CNA constrói uma base para práticas de pesquisa em campos como a Antropologia Cognitiva e Cultural, Psicologia Cognitiva e Análise de Decisões. Esse método oferece um conjunto de técnicas para construir modelos culturais para grupos, organizações e sociedades mais amplas. A CNA discrimina três tipos de ideias: conceitos, valores e crenças sobre relações causais. Os modelos culturais derivados da CNA são representados graficamente como uma rede de conceitos culturalmente compartilhados, crenças causais e valores que influenciam decisões chaves num contexto particular. Esses diagramas representam como as ideias se inter-relacionam. Conforme Sieck, essa abordagem inclui um conjunto de técnicas para construir diagramas de modelos mentais. Os métodos visam "extrair as ideias" de transcrições de entrevistas ou outros textos e analisar o quão comuns essas ideias são entre os e dentro dos grupos culturais analisados. Essas ideias compartilhadas são organizadas, então, em mapas (SIECK, 2011).

Conforme o autor, a CNA compreende uma fase exploratória e uma fase confirmatória. Na primeira, conceitos e modelos mentais são extraídos de fontes qualitativas, tais como entrevistas e mídia aberta (por exemplo, web, blogs), com o objetivo de desenvolver um entendimento preliminar dos conceitos e características culturalmente relevantes no referido domínio, assim como de obter representações gráficas iniciais dos modelos mentais das pessoas de uma forma aproximada à sua estrutura representacional natural. $\mathrm{Na}$ segunda fase, são realizadas entrevistas estruturadas, experimentos de campo, e mineração semântica automatizada de fontes baseadas na web para obter dados sistemáticos passíveis de análise estatística. Essas análises são utilizadas para avaliar os padrões e derivar estatísticas que descrevem a distribuição de conceitos, crenças causais e valores. Em seguida, são construídas as representações formais dos modelos culturais que ilustram a informação estatística e qualitativa em diagramas. 
Sieck (2011) afirma que os terroristas tentam moldar o ponto de vista de seu alvo de audiência comunicando aspectos específicos de sua ideologia. Para que sejam bemsucedidos, as ideias que promovem devem ajustar-se a um sistema de significados culturais compartilhados entre uma população-alvo. Desse modo, é necessário um método que possibilite estudar a perspectiva comum dos membros de uma cultura. $\mathrm{O}$ resultado seriam modelos culturais que fornecem uma base para outsiders começarem a enquadrar eventos a partir do ponto de vista do insider da referida cultura. Ao mesmo tempo, esses modelos culturais podem ser usados para antecipar o modo como as mensagens serão interpretadas e avaliadas tanto pelos terroristas como pela sua audiência-alvo.

Uma das aplicações dessa "modelagem cultural" é mapear explicitamente os sistemas de significado cultural relevantes para entender como e por que várias mensagens parecem ser eficazes em influenciar as atitudes das pessoas e angariar seu apoio. Para Sieck, os terroristas atuam e recrutam a partir de fatores que interagem entre si, tais como: aspirações políticas desses grupos, vulnerabilidade dos indivíduos, emprego da ideologia jihadista e apoio social à sua causa. A interação entre esses fatores depende de diferentes modos de comunicação que propagam essa visão de mundo. As estratégias de comunicação das organizações jihadistas, então, motivam pessoas comuns a realizarem atos terroristas de acordo com os objetivos de sua organização, exploram injúria moral e sentimentos de humilhação relativos a eventos políticos e convencem sua audiência-alvo por meio de textos religiosos em favor da ideologia terrorista.

É importante observar, quanto à questão da vulnerabilidade dos indivíduos, o exemplo de um trecho que Sieck traz de uma entrevista com um recruta terrorista no Pakistão: "nenhum tinha baixa instrução, era desesperadamente pobre, simplório ou depressivo" e "todos eram profundamente religiosos", de modo que seus atos eram "sancionados pela religião do Islam, divinamente revelada" (2011, p. 4). Entretanto, Sieck afirma que "isso não significa que a raiz da motivação terrorista seja a religião, apenas que crenças e valores religiosos são um importante componente das descrições de mundo dos grupos jihadistas" (p. 4).

O modelo cultural proposto por Sieck, conforme Figura 1 na página seguinte, toma em consideração a concepção extremista Sunita muçulmana de relações sociopolíticas entre o Islam e o ocidente. Ele contém conceitos individuais de uma pessoa assim como seus entendimentos das relações causais entre as atividades políticas e seus resultados.

A Figura 1 apresenta o resultado da modelagem a partir do corpus utilizado por Sieck (2011). São utilizados círculos, setas e cores. Dentro dos círculos são apresentadas "ideias simples". As setas indicam a direção das relações causais (+/-). Por exemplo: o desenvolvimento de um novo califado islâmico diminuiria (-) a extensão do domínio ocidental, ao mesmo tempo em que promove $(+)$ o retorno de um passado de glória islâmica. As cores indicam ideias ou valores desejáveis (cor verde) pelos jihadistas sunitas.

Esse modelo, para o autor, influencia as expectativas dos indivíduos de como as relações sociopolíticas se desdobrarão, fornecendo um enquadre para selecionar comportamentos e objetivos em dado contexto.

Diferentemente dos demais modelos, este não se estrutura proposicionalmente, tendo, conforme a CNA uma estrutura em rede. 
Figura 1 - Modelo cultural JIHADISTA SUNITA de relações políticas

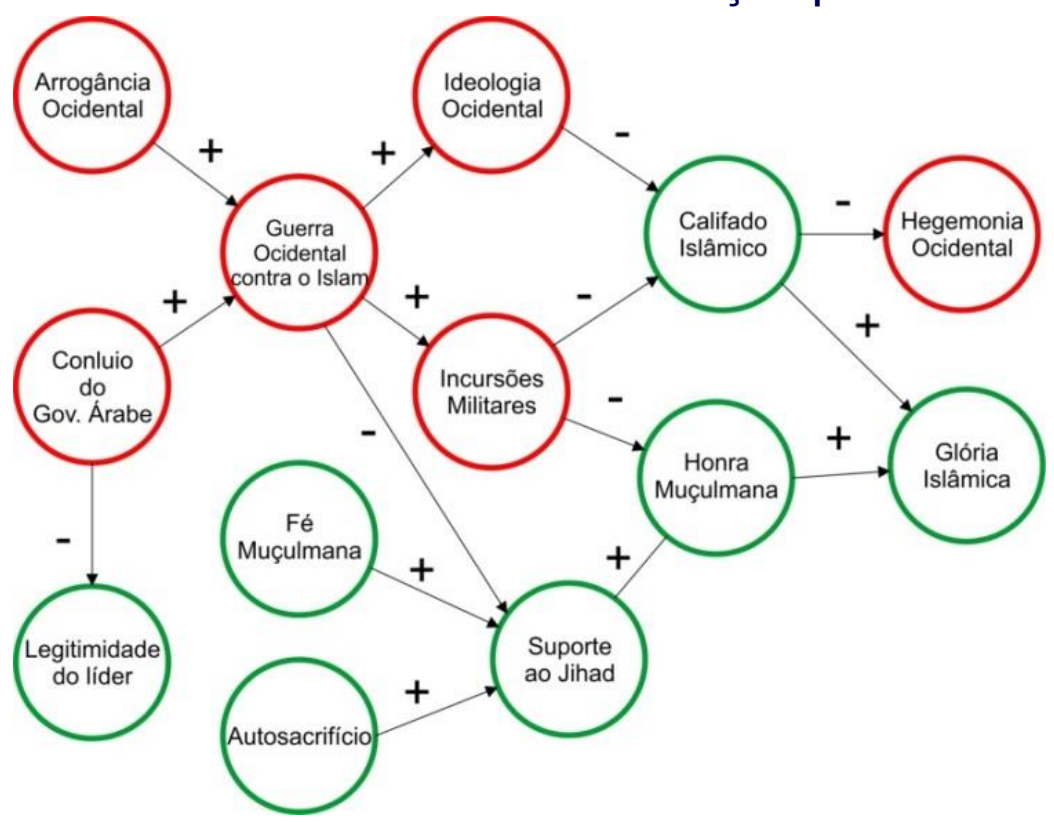

Fonte: Sieck (2011, p. 7), traduzido e adaptado pela autora.

\section{O PROBLEMA DA CONSTRUÇÃO E ANÁLISE DE MODELOS CULTURAIS}

Tendo apresentado, na seção 3, exemplos de estudos que ilustram a (re)construção de modelos culturais, é importante trazer, aqui, o ponto de vista de Kessing (1987) sobre questões problemáticas relacionadas a aspectos metodológicos no tratamento de modelos culturais, antes de, no final do artigo, apresentarmos alguns métodos utilizados para investigar modelos culturais.

Segundo esse antropólogo, passou-se do uso de 'modelos folk' para 'modelos culturais' (expressão esta que chama de versão mutante de modelos folk') como uma reformulação ou reconceptualização. Porém, a denominação 'folk' visava estabelecer uma diferença com os modelos de experts, criando-se, assim, a dicotomia folk/experts.

Aceitando-se a reconceptualização e a intercambialidade dos termos, Kessing entende que a visão cognitiva de cultura permite, potencialmente, interpretar a distribuição e a variabilidade do conhecimento, assim como a coconstrução de mundos compartilhados. Assim, as noções de modelos folk e modelos culturais permitem capturar, ao mesmo tempo, o que é cultural e público e o que é cognitivo. Entende que as regras culturais são historicamente situadas, moldadas, mas não determinadas, por aspectos econômicos e ecológicos, assim como por processos sociais, de modo que "o conhecimento cultural não varia meramente de indivíduo para indivíduo" (p. 387).

Entre várias questões que o autor levanta, há algumas que merecem mais atenção. Kessing (1987) questiona: Como definir modelos folk ou culturais de modo que eles sejam úteis para delimitar alguns setores do conhecimento cultural dos indivíduos? Ou, mais sucintamente, o que são tais modelos? E o que os seres humanos sabem que não incluem esses modelos? O que faz deles "modelos"? Para responder a essas questões, o autor assinala duas dimensões a serem analisadas: (a) o compartilhamento como construções 
folk ou culturais; e (b) seu caráter de modelo. Quanto a (a), a questão é que tais modelos têm a natureza de senso comum, abarcam domínios culturalmente construídos de senso comum e servem a propósitos pragmáticos. De um modo amplo, modelos culturais "explicam o tangível, o experiencial [...], o provável; assumem uma geologia superficial de causação; mantêm a influência num domínio em que exceções confirmam a regra, e as contradições convivem de forma feliz" (KESSING, 1987, p. 374). Quanto a (b), a natureza dos modelos culturais é paradigmática, é de "propor mundos", que são simplificados e interna ou externamente contraditórios. Eles não são apresentados a nós por meio do que as pessoas dizem ou fazem em sua vida cotidiana, eles são, em vez disso, representados a partir de facetas fragmentadas superficiais. Desse modo, temos de inferir os mais coerentes, se inarticulados, modelos subjacentes.

O autor é bastante crítico com relação ao caráter cognitivo de modelos folk e culturais. E adverte:

Se nossos modelos de modelos de outras pessoas devem ajustar-se às conceptualizações da ciência cognitiva e, ao mesmo tempo, ajustar-se ao empreendimento antropológico mais amplo, precisamos elaborar questões estratégicas sobre a estrutura do conhecimento cultural e o modo como é utilizado na vida social em curso. (KESSING, 1987, p. 381)

Um aspecto extremamente importante a ser observado, segundo Kessing, é o "processo de eliciação" na relação entre modelos culturais, experiência individual e fatores situacionais. A questão provocativa é se o pesquisador e seus informantes não acabam entrando em um processo de "cocriação". Estaríamos criando modelos mais globais e mais coerentes do que nossos sujeitos conhecem? O autor tem a preocupação com a possibilidade de "modelos folk ou culturais não existirem até que nossas estratégias de questionamento levem os informantes a criá-los, ou, pior ainda, até que suas respostas forneçam fragmentos a partir dos quais nós os criamos” (p. 383).

Outra crítica do autor diz respeito ao perigo de imputar aos nossos sujeitos teorias metafísicas que parecem ser implicadas pelas formas convencionais de falar. Essa crítica tem por base justamente a obra de Lakoff e Johnson (1980) e o estudo sobre raiva de Lakoff e Kövecses (1987). Kessing questiona: Em que medida as metáforas convencionais e os esquemas que elas expressam são constitutivos de nossa experiência? Esquemas variados (por exemplo, de emoções, tempo, causalidade, relações sociais) refletem formas da experiência subjetiva, do pensamento e da percepção, ou meramente refletem convenções diferentes para falar sobre o mundo experienciado a partir do tipo de cérebro, equipamento sensório e corpo que temos?

A observação mais radical de Kessing aos estudos sobre modelos culturais é o fato de que se deve ter em vista a produção, o controle, a distribuição e a força ideológica do conhecimento cultural, incorporando os sistemas cognitivos que são explorados e mapeados dentro de sistemas sociais, atentando para o lugar que essas investigações ocupam nos avanços multidisciplinares das ciências sociais e comportamentais. Isso porque os sistemas sociais são construídos a partir do e restringidos pelo que os seres humanos são; e o modo como os seres humanos conhecem seus mundos restringe e molda a forma como os humanos-em-sociedade os reproduzem. Desse modo, explorar modelos 
conceptuais, metáforas, construções e coconstruções de significado pode trazer importantes contribuições para o complexo entendimento dos seres humanos-emsociedade. Entretanto, faz a ressalva de que seria esperar demais de antropólogos cognitivos e outros estudiosos de modelos conceptuais da realidade cotidiana que fossem, para além disso, teóricos sociais.

\section{CONSIDERAÇÕES FINAIS: MODELOS CULTURAIS E MÉTODOS}

Bennardo e Munck (2014) apresentam uma metodologia de análise de modelos culturais em termos de uma trajetória de quatro passos: partir de dados e análises etnográficas (por exemplo, observação participante), seguindo-se, então, para dados e análises linguísticas (por exemplo, análise interpretativa de texto, de entrevistas, com foco na palavra, na sentença, no discurso) e dados e análises experimentais (por exemplo, questões free-list, tarefas pile sorts, eliciação de frames, tarefas de memória, tarefas de rating), culminando com análise de consenso (com questionários e entrevistas estruturadas $)^{6}$. Os autores reconhecem que muitas pesquisas privilegiam alguns tipos de dados e de análises em detrimento de outros e, raramente, uma investigação segue os quatro passos da metodologia proposta.

Quinn e Holland (1987) revelam que alguns antropólogos admitem a limitação de um programa de pesquisa que valide modelos culturais apenas baseados no comportamento linguístico, pois as pessoas nem sempre fazem o que pareceria ser uma consequência das crenças que elas enunciam linguisticamente. Por isso, para reconstruir modelos culturais é necessário ir além de sua influência sobre a fala. Afirmam que a complexidade da relação entre o que as pessoas verbalizam sobre o que elas fazem e a execução de outras atividades não verbais deve-se ao fato de que elas ordinariamente se ocupam com tarefas complexas, com muitos objetivos que podem ou não incluir a produção de uma descrição verbal "verídica" (sobre tais objetivos). Isso inclui, por exemplo, agir de um modo que traga vantagens pessoais, apresentar objetivos de um ponto de vista que lhes seja favorável, ou, então, conduzir planos ocultando os seus verdadeiros objetivos. De acordo com as autoras, ao fazerem isso, os falantes não evocam conceitualizações diferentes sobre a atividade sobre as quais elas falam, eles apenas evocam entendimentos culturais pertinentes à realização da parte linguística relativa à tarefa num dado momento: querem se mostrar sob um ponto de vista favorável, querem ser vistos como boas pessoas, querem distrair a atenção dos demais com relação aos seus reais motivos, etc. Ainda assim, para as autoras, "a maior fonte de dados que os antropólogos cognitivos têm adaptado para a tarefa de reconstruir modelos culturais [...] são duas: uso sistemático das intuições de falantes nativos e análise de discurso natural" (QUINN; HOLLAND, 1987, p. 16).

As autoras ressaltam duas questões fundamentais: enquanto a questão teórica envolvida é a de como o conhecimento cultural está organizado, a questão estratégica seria "reconstruir a organização desse conhecimento compartilhado a partir do que as

\footnotetext{
${ }^{6}$ É um método estatístico que procura medir as semelhanças/o consenso entre pessoas por meio de um perfil de respostas. Para detalhes desse tipo de análise, ver Bennardo e Munck (2014, p. 93-99).
} 
pessoas dizem sobre suas experiências" (1987, p. 18, grifo nosso). Para tanto, comentam, a Antropologia Cognitiva tem adotado algumas das abordagens teóricas da Linguística, sendo a análise semântica "um método poderoso conveniente". Porém, os esforços atuais nos empreendimentos etnocientíficos "estão mais voltados para a construção de uma teoria do que seguir qualquer metodologia particular" (p. 18).

Quinn (1987) afirma que a razão de os antropólogos terem "rápida e acriticamente" incorporado a suposição de que a metáfora estrutura ou fornece um modelo para o entendimento daquilo que ela captura foi, talvez, a falta de uma teoria mais desenvolvida de significado cultural. A autora defende que, apesar de a linguagem conter pistas para um esquema cultural, este tanto não é isomórfico à linguagem como não é óbvio a partir dela, assim como não é recuperado a partir de qualquer metáfora utilizada pelo falante. $\mathrm{E}$ conclui que a "reconstrução de tais esquemas culturais a partir de pistas indiretas fornecidas pela linguagem requer um método apropriadamente sensível" (QUINN, 1997, p. 144).

Strauss (2014), por sua vez, a partir de diferentes autores, afirma que os pesquisadores de modelos culturais debruçam-se sobre discursos extensos, buscando o que é pressuposto a partir do que é dito; que não se deve questionar diretamente o informante sobre dado modelo cultural, mas que se pergunte a ele sobre algo que o faça usar o modelo cultural em sua resposta; que entrevistas semiestruturadas longas são típicas em tais estudos; que a observação participante é difícil porque o tópico em questão surge em momentos imprevisíveis da vida cotidiana, de modo que não se obtêm falas extensas para serem analisadas; e que outros tipos de discursos podem ser coletados, tais como: provérbios, histórias e comunicações online.

Seguimos o ponto de vista de Quinn e Holland (1987), segundo o qual não existem procedimentos mecânicos que permitam derivar um modelo cultural a partir dos domínios semânticos a que se faz referência. Entendemos, ainda, que a linguagem possa fornecer pistas sobre o comportamento cultural a partir de diferentes fontes de dados e, finalmente, que se deva explorar de forma eclética várias fontes de dados e diferentes tipos de análises. Na mesma direção, seguimos o ponto de vista de Strauss (2014) para quem novas questões e novos métodos têm como resultado abordagens "mais ecumênicas" (p. 394).

Da mesma forma, como Bennardo e Munck (2014), de fato entendemos que a linguagem é uma "entrada privilegiada" para a mente ou para a estruturação mental do conhecimento, pois análises detalhadas de dados linguísticos revelam, pelo menos em parte, a organização do significado na mente e a organização cognitiva do conhecimento. Desse modo, "descobrir conteúdo e estrutura semântica específicas fornece insights plausíveis sobre a organização cognitiva geral e sobre o processamento do conhecimento" (p. 49).

É importante observar, seguindo a revisão teórica de Strauss (2014) que nem todas as crenças são internalizadas e representadas proposicionalmente. Há casos em que as suposições são aprendidas como fortes conexões em uma rede neural, estando ou não as pessoas delas conscientes. Desse modo: "Enquanto os analistas devem usar a linguagem para descrever aquilo em que as pessoas acreditam, o conteúdo cognitivo de conhecimento cultural não é necessariamente discursivo, e o processo de pensamento inclui tanto elementos verbais como não verbais" (p. 396). 
A interface dos estudos linguísticos com as antropologias cognitivas promoveu a incorporação de muitas "variáveis" socioculturais aos estudos semânticos e na Linguística Cognitiva como um todo. Analisar sob diferentes perspectivas a questão dos modelos culturais é uma forma de dar relevância a interfaces emergentes que promovem debates mais vigorosos e, por consequência, mais profícuos em Linguística Cognitiva.

\section{REFERÊNCIAS}

BENNARDO, G.; MUNCK, V. C. Cultural models: genesis, methods, and experiences. New York: Oxford University Press, 2014.

D’ANDRADE, R. Schemas and motivation. In: D’ANDRADE, R.; STRAUSS, C. (Ed.) Human motives and cultural models. New York: Cambridge University Press, 1992. p. 23-44.

D'ANDRADE, R. The development of cognitive anthropology. New York: Cambridge University Press, 1995.

FELTES, H. P. de M. Semântica cognitiva: ilhas, pontes e teias. Porto Alegre: Edipucrs, 2007.

KESSING, R. M. Models, “folk” and "cultural”: paradigms regained? In: HOLLAND, D.; QUINN, N. (Ed.) Cultural models in language and thought. Cambridge: Cambridge University Press, 1987. p. 369393.

KÖVECSES, Z. Metaphor and folk understanding of anger. In: RUSSELL, J. A.; FERNÁNDEZ-DOLS, J-M.; MANSTEAD, A. S. R.; WELLENCAMP, J. C. (Ed.) Everyday conceptions of emotions: an introduction to psychology, anthropology and linguistics of emotion. Springer-Science+Business Media Dordrecht, NATO ASI Series, S. D. Behavioural and Social Science, v. 81, p. 49-72, 1995.

KÖVECSES, Z. Metaphor in culture: universality and variation. Cambridge: Cambridge University Press, 2005.

KRONENFELD, D. B. Culture, society, and cognition: collective goals, values, action, and knowledge. New York: Mouton de Gruyter, 2008.

LAKOFF, G. Women, fire, and dangerous things: what categories reveal about the mind. Chicago: The University of Chicago Press, 1987.

; JOHNSON, M. Metaphors we live by. Chicago: University of Chicago Press, 1980.

York: Basic Books, 1999.
; KÖVECSES, Z. The cognitive model of anger inherent in American English. In: HOLLAND,

D.; QUINN, N. (Ed.) Cultural models in language and thought. Cambridge: Cambridge University Press, 1987. p. 195-221.

MINSKY, M. A framework for representing knowledge. In: WINSTON, P. (Ed.) The psychology of computer vision. New York: McGraw-Hill, 1975. p. 211-277.

PALMER, G. B. Cognitive Linguistics and Anthropological Linguistics. In: GEERAERTS, D.; CUYCKENS, H. (Ed.) The Oxford handbook of Cognitive Linguistics. New York: Oxford University Press, 2007. p. 1045-1073.

QUINN, N. Convergent evidence for a cultural model of American marriage. In: HOLLAND, D.; p. 173-192.

(Ed.) Cultural models in language and thought. Cambridge: Cambridge University Press, 1987.

Research on shared task solution. In: STRAUSS, C.; QUINN, N. A Cognitive theory of cultural meanings. Cambridge: Cambridge University Press, 1997. p. 137-188.

; HOLLAND, D. Culture and cognition. In: HOLLAND, D.; QUINN, N. (Ed.) Cultural models in language and thought. Cambridge: Cambridge University Press, 1987. p. 3-40.

SIECK, W. R. A cultural models approach for investigating the cognitive basis of terrorism. Journal of Terrorism Research, v. 2, n. 1, p. 3-15, 2011. 
; RASMUSSEN, L. J.; SMART, P. R. Cultural network analysis: a cognitive approach to cultural modeling. In: VERMA, Dinesh (Ed.). Network science for military coalition operations: information extraction and interaction. Hershey, Pennsylvania, 2010. p. 237-255.

SPERBER, D. Anthropology and psychology: towards an epidemiology of representations. Man, New Series, v. 20, n. 1, p. 73-89, mar. 1985.

STRAUSS, C. Language and culture in cognitive anthropology. In: SHARIFIAN, F. (Ed.) The Routledge handbook of language and culture. New York: Routledge, 2014. p. 386-400.

\section{Recebido em: 07/08/17. Aprovado em: 14/12/17.}

Title: Cultural models: theory, studies and methods

Author: Heloísa Pedroso de Moraes Feltes

Abstract: This paper is a theoretical review about the construct of cultural models, firstly focusing its definition on Cognitive Anthropology, Cognitive Linguistics and Anthropological Linguistics. Subsequently presents, as an example, four studies on Cognitive Linguistics and Cognitive Anthropology about cultural models that have different methodologies, techniques and procedures: the one of the ANGER, the one of the RATIONALIST AND ROMANTIC OF THE LINGUISTIC STANDARDIZATION, the one of MARRIAGE, and the one of the POLITICAL RELATIONS OF SUNNI JIHADIST. Next, it is brought a brief discussion up on problem questions to be raised in the treatment of cultural models according to Cognitive Anthropology. The final considerations developed a general analysis of the main methods in investigations about cultural models.

Keywords: Cultural Models. Cognitive Linguistics. Cognitive Anthropology. Methods.

Título: Modelos culturales: teoría, estudios y métodos

Autora: Heloísa Pedroso de Moraes Feltes

Resumen: Este artículo es una revisión teórica sobre el constructo modelos culturales, con foco inicial en sus definiciones en Antropología Cognitiva, Lingüística Cognitiva y Lingüística Antropológica. Presenta, en seguida, cómo ejemplo, cuatro estudios en Lingüística Cognitiva y Antropología Cognitiva sobre modelos culturales que siguen metodologías, técnicas y procedimientos diferentes: de RABIA, RACIONALISTA Y ROMÁNTICO DE ESTANDARIZACIÓN LINGÜÍSTICA, de CASAMIENTO, y JIHADISTA SUNITA DE RELACIONES POLÍTICAS. En secuencia trae una breve discusión sobre cuestiones-problema que serán levantadas en el tratamiento de modelos culturales en Antropología Cognitiva. Las consideraciones finales desarrollan un análisis general de los métodos priorizados en investigaciones sobre modelos culturales.

Palabras clave: Modelos Culturales. Lingüística Cognitiva. Antropología Cognitiva. Métodos.

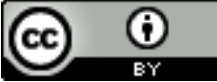

Este texto está licenciado com uma Licença Creative Commons Atribuição 4.0 Internacional. 